\title{
PUBLICAÇÕES INTERNACIONAIS SOBRE SUSTENTABILIDADE: UMA REVISÃO DE ARTIGOS COM O USO DA TÉCNICA DE ANÁLISE DE CONTEÚDO QUALITATIVA
}

\author{
INTERNATIONAL PUBLICATIONS ABOUT \\ SUSTAINABILITY: A REVIEW OF ARTICLES USING THE \\ TECHNIQUE OF QUALITATIVE CONTENT ANALYSIS
}

Recebido 16-09-2012 Aceito 19-03-2013

Cristiane Froehlich ${ }^{1}$

\section{RESUMO}

Esta pesquisa tem como objetivo analisar as categorias que emergem de artigos relacionados ao tema da sustentabilidade em publicações internacionais, por meio do uso da técnica de análise de conteúdo qualitativa, buscando identificar as principais abordagens, contribuições, lacunas teóricas e sugestões para novos estudos. Para aplicação da técnica, foram analisados 20 artigos sobre sustentabilidade em Journals que apresentam fator de impacto relevante, com base nas três etapas básicas para análise de conteúdo das publicações indicadas por Bardin (1977, 2010): (a) pré-análise; (b) exploração do material; (c) e tratamento dos dados, inferência e interpretação. Os resultados encontrados demonstram que as principais teorias que são associadas ao tema da sustentabilidade são: a teoria dos recursos e capacidades, a teoria institucional, a teoria dos stakeholders, a teoria da orientação de mercado do marketing, a teoria da cadeia produtiva e a vantagem competitiva. Todas buscam contribuir e explicar os fatores que facilitam e dificultam as práticas de sustentabilidade corporativa. Além disso, algumas sugestões para novas pesquisas foram identificadas e apresentadas na análise dos resultados deste estudo.

Palavras-chave: Sustentabilidade. Análise de Conteúdo. Qualitativa.

${ }^{1}$ Possui graduação em Pedagogia pela Universidade do Vale do Rio dos Sinos - UNISINOS, especialização em Gestão e Planejamento de Recursos Humanos pela Universidade do Vale do Rio dos Sinos - UNISINOS, mestrado e doutorado em Administração pela Universidade do Vale do Rio dos Sinos - UNISINOS. Atualmente é professora da FEEVALE e da Universidade do Vale do Rio dos Sinos - UNISINOS. Novo 


\section{ABSTRACT}

This study aims to identify articles related to sustainability in international publications and analyze the categories that emerge from these studies through the use of the technique of qualitative content analysis in order to identify the main approaches, author contributions and theoretical gaps and suggestions for further studies. For application of the technique have been rising about 20 articles in Journals that feature sustainability impact factor relevant, and used the three basic steps for content analysis of the publications listed by Bardin (1977): (a) pre-analysis; (b) material exploration and; (c) treatment data, inference and interpretation. The main results show that the major theories that are related to sustainability are: the resources and capabilities theory, institutional theory, stakeholders theory, the theory of market orientation, theory of supply chain and competitive advantage and both seek to help and explain the factors that facilitate or hinder the practice of corporate sustainability. In addition, some suggestions for further research were identified and analysis of the results presented in this study.

Keywords: Sustainability. Content Analysis. Qualitative.

\section{INTRODUÇÃO}

A discussão sobre sustentabilidade e/ou desenvolvimento sustentável é vasta e abrange desde estratégias e ações desenvolvidas no âmbito das nações até estratégias e ações especificamente relacionadas à responsabilidade social e ambiental no contexto empresarial. Nesse sentido, embora se reconheça a contribuição teórica (BANSAL, 2005; GLADWIN et al, 1995; SACHS,1993) que já existe neste campo, o conceito de sustentabilidade ainda está em fase de construção e precisa ser estudado com maior profundidade e rigor para sua melhor compreensão.

No Brasil, a sustentabilidade passou a ser considerada estratégica a partir da década de 1990, devido à mudança no patamar de atuação das empresas brasileiras, possibilitada pelo maior grau de internacionalização e pelo desenvolvimento do mercado global de capitais, dentre outros. Com isso, as empresas passaram a ser cobradas, tendo de assumir sua parcela de responsabilidade com a sociedade (ZYLBERSZTAJN; LINS, 2010).

Desse modo, sob a atual pressão mercadológica e da sociedade, a empresa que não incorporar o conceito de sustentabilidade em sua gestão de negócios (na prática e não apenas em seu discurso) terá dificuldades de sobreviver às próximas décadas, segundo Zylbersztajn e Lins (2010). Cada vez mais, as empresas são consideradas responsáveis não só por suas próprias atividades, mas também pelas dos fornecedores, das comunidades em que atuam e das pessoas que usam seus produtos.

A escolha do tema sustentabilidade justifica-se, pois essa temática suscita várias críticas devido ao seu amplo conteúdo, podendo ser interpretado como um novo modelo de desenvolvimento ou apenas um redesenho do capitalismo. Cada vez mais, empresas estão implementando estratégias orientadas para a sustentabilidade, e, da mesma forma, vários pesquisadores dedicam-se a estudar esse tema. No entanto, percebem-se, neste processo, diferentes opiniões e enfoques sobre como lidar com questões relacionadas à sustentabilidade.

Diante desse contexto, tem-se a necessidade de verificar alguns aspectos. Como os autores vêm trabalhando o tema da sustentabilidade em publicações internacionais? Quais são as principais teorias da administração a que o tema é relacionado? Quais são as categorias que emergem dessas pesquisas? Quais são as contribuições e os avanços que esses estudos trouxeram para o campo científico em questão? Quais são as lacunas que esses artigos apresentam? Como a técnica de análise de conteúdo qualitativa pode facilitar a busca de respostas para as questões apresentadas?

Assim, este estudo tem como objetivo identificar artigos relacionados ao tema da sustentabilidade em publicações internacionais e analisar as categorias que emergem desses artigos por meio do uso da técnica de análise de conteúdo qualitativa, buscando identificar as principais 
abordagens, contribuições, lacunas teóricas e sugestões para novos estudos.

Para responder as questões e os objetivos desta investigação, o uso da técnica de análise de conteúdo de dados qualitativos é indicado. No campo científico da administração no Brasil, há crescente interesse pela análise de conteúdo como técnica de análise de dados qualitativos. A importância da análise de conteúdo para os estudos organizacionais é cada vez maior e tem evoluído em virtude da preocupação com o rigor científico e com a profundidade das pesquisas.

Para Flick (2005), a análise do conteúdo é um procedimento metodológico para análise de material textual. Um de seus aspectos essenciais é o emprego de categorias, obtidas, com frequência, de modelos teóricos: as categorias são trazidas para o material empírico e não necessariamente desenvolvidas a partir deste, embora sejam, repetidas vezes, avaliadas contrastivamente e, se necessário, modificadas. O objetivo principal é reduzir o material.

Para aplicação da técnica de análise de conteúdo qualitativa, foram levantados artigos sobre sustentabilidade publicados em revistas científicas internacionais, que foram escolhidas com base em seu fator de impacto e na relação entre sua política editorial e o tema em estudo. Para atender ao objetivo deste estudo, apresentam-se, na fundamentação teórica, os conceitos, as origens e as dimensões no contexto empresarial do tema sustentabilidade. A seguir, são abordadas as características da técnica de análise de conteúdo, os passos necessários para sua utilização e suas limitações. Após, aborda-se a metodologia desta pesquisa, apresenta-se a análise dos resultados e, por fim, as considerações finais.

\section{SUSTENTABILIDADE - ORIGEM, CONCEITUAÇÕES E DIMENSÕES}

Na década de 70, começaram a surgir publicações científicas a respeito dos desequilíbrios causados na terra pelo avanço da industrialização. A obra "Os Limites do Crescimento", de autoria do Clube de Roma, grupo formado por pesquisadores e empresários, ganhou destaque internacional quando se fez presente nas discussões da Conferência das Nações Unidas de Estocolmo, em 1972. A publicação focava a preservação ambiental, apresentando quatro temas centrais: crescimento populacional; crescimento industrial; escassez de alimentos; e escassez de recursos naturais. Esses temas necessitavam ser debatidos com urgência para que fosse possível retomar o equilíbrio ambiental (COMISSÃO MUNDIAL SOBRE MEIO AMBIENTE E DESENVOLVIMENTO, 1991).

Em 1983, as Nações Unidas criaram a Comissão Mundial de Meio Ambiente e Desenvolvimento, presidida por Gro Bruntland. Essa comissão tinha como objetivo propor novas normas de cooperação internacional que pudessem orientar políticas e ações internacionais de modo a promover as mudanças que se faziam necessárias. O trabalho da Comissão gerou como resultado, em 1987, o Relatório Bruntland, conhecido como "Nosso Futuro Comum" (COMISSÃO MUNDIAL SOBRE MEIO AMBIENTE E DESENVOLVIMENTO, 1991).

O conceito de desenvolvimento sustentável foi definido como um modo de satisfazer as necessidades do presente sem comprometer a capacidade das gerações futuras de satisfazer as próprias necessidades (WCED, 1987). Desse modo, surgiu o conceito de "Desenvolvimento Sustentável", que, anos mais tarde, passou a ser adotado como termo oficial nos documentos da ONU.

Dessa forma, o conceito mais comumente considerado em pesquisas é o do relatório Brundtland da World Commission for Economic Development (WCED, 1987). Nesse relatório, o desenvolvimento sustentável é tido como um processo de mudanças, em que a exploração de recursos, a direção dos investimentos, a orientação do desenvolvimento tecnológico e as alterações institucionais são realizadas de maneira consistente com as necessidades atuais e futuras (BANERJEE, 2002). 
Em 1992, realizou-se a Conferência das Nações Unidas para o Meio Ambiente e Desenvolvimento no Rio de Janeiro, que ficou conhecida como Eco 92 ou Cúpula da Terra. Um dos resultados dessa Conferência foi a aprovação do documento "Agenda 21". Este documento ressalta a preparação do mundo para os desafios do século XXI por meio de um plano de ação com os objetivos a serem atingidos pelas sociedades para sustentar a vida no planeta (UNCED, 1992). Outras conferências das Nações Unidas para o Meio Ambiente e Desenvolvimento, como a Rio+5 e Rio+10, aconteceram, respectivamente, em 1997 e 2002, em Johanesburgo, objetivando revisar a implementação da Agenda 21, a fim de reafirmar compromissos e propor novas ações.

Em 1997, criou-se a Comissão da Carta da Terra. A ideia surgiu ainda na Eco 92 em função do descontentamento de organizadores da ONU. Composta por personalidades de vários países, a comissão escutou milhares de pessoas de diversas comunidades espalhadas pelo mundo e, em 2000, no espaço da UNESCO, em Paris, a Carta da Terra foi aprovada (ONU, 2000).

Ainda em 2000, a ONU promoveu a Assembleia do Milênio, em um encontro que reuniu 191 delegações e contou com a presença dos principais chefes de estado do mundo. O debate resultou na Declaração do Milênio, documento que consolidou várias metas estabelecidas nas conferências mundiais ocorridas na década de 90 , propondo objetivos para a erradicação da pobreza no mundo. Oito objetivos gerais foram identificados: erradicar a extrema pobreza e a fome; atingir o ensino básico universal; promover a igualdade de gênero e a autonomia das mulheres; reduzir a mortalidade infantil; melhorar a saúde materna; combater o HIV/AIDS, a malária e outras doenças; garantir a sustentabilidade ambiental; e estabelecer uma parceria mundial para o desenvolvimento. Em 2006, a ONU estipulou, ao Brasil, um nono objetivo: "igualdade entre brancos e negros". A intenção é que os estados membros das Nações Unidas não meçam esforços para cumprir os ODM (Objetivos da Declaração do Milênio) até 2015 (ONU, 2006).

No final do século XX, a ONU (2000) lançou a ideia de parceria entre as Nações Unidas, ONGs e empresas com o objetivo de obter convergência entre as práticas do setor privado e valores universais. A ideia ganhou corpo e nome: Global Compact ou Pacto Global. Fundamentado na Declaração Universal da Organização Internacional do Trabalho e na Declaração do Meio Ambiente de Desenvolvimento (Eco 92), o pacto visa criar uma economia global mais inclusiva e sustentável, baseando-se em dez princípios: respeitar e proteger os direitos humanos; impedir violações de direitos humanos; apoiar a liberdade de associação no trabalho; abolir o trabalho forçado; abolir o trabalho infantil; eliminar a discriminação no ambiente de trabalho; apoiar uma abordagem preventiva aos desafios ambientais; promover a responsabilidade ambiental; encorajar tecnologias que não agridam o meio ambiente; e lutar contra toda forma de corrupção.

Em junho de 2012, realizou-se a Conferência das Nações Unidas em Desenvolvimento Sustentável - Rio+20 - no Rio de Janeiro com o objetivo de renovar o compromisso político com o desenvolvimento sustentável, por meio da avaliação do progresso e das lacunas na implementação das decisões adotadas pelas principais cúpulas sobre o assunto e do tratamento de temas novos e emergentes (UNCED, 2012).

Pode-se dizer que a definição abrangente de Brundtland está na raiz de muitas controvérsias e há um considerável desacordo entre estudiosos de diferentes áreas a respeito de "como" ela pode ser operacionalizada e de que maneira a sustentabilidade pode ser mensurada. Além de tentar reconciliar o crescimento econômico com a preservação do meio ambiente, a agenda de Brundtland enfatiza a justiça social e o desenvolvimento humano dentro do quadro de referência da equidade social e da distribuição e utilização equitativa dos recursos naturais. A sustentabilidade, conforme Redfclift (1987), significa coisas diferentes para diferentes povos; embora as teorias de sustentabilidade enfatizem a primazia da justiça social, a posição é frequentemente invertida, 
ficando a justiça subordinada à sustentabilidade. Como nem sustentabilidade nem justiça têm significados claros, abre-se o caminho para legitimar um dos termos em referência ao outro.

Pode-se observar que o conceito de sustentabilidade é inspirado por múltiplos objetivos, por interdependências complexas e consideráveis. Sustentabilidade, na prática, pode ser encarada como a arte de fazer negócios em um mundo interdependente. Sustentabilidade, no sentido mais amplo do termo, tem tudo a ver com interdependência, que assume várias formas, de acordo com Savitz e Weber (2007).

Desse modo, sustentabilidade é o respeito à interdependência dos seres vivos entre si e em relação ao meio ambiente. Sustentabilidade significa operar a empresa sem causar danos aos seres vivos e sem destruir o meio ambiente; é, ao contrário, fazer isso restaurando-o e enriquecendo-o. Sustentabilidade também é observância da interdependência de vários elementos da sociedade, entre si e em relação ao tecido social. Sustentabilidade é reconhecimento das necessidades e dos interesses das outras partes (grupos comunitários, instituições educacionais e religiosas, força de trabalho e população), no sentido de reforçar a rede de relacionamentos que as mantêm integradas (SAVITZ e WEBER, 2007).

Para Savitz e Weber (2007), a empresa sustentável é aquela que gera lucro para os acionistas, ao mesmo tempo em que protege o meio ambiente e melhora a vida das pessoas com quem mantém interações. Hawken (1993) entende sustentabilidade como um estado econômico em que as demandas colocadas no ambiente, por pessoas e pelo comércio, podem ser atendidas sem diminuir as capacidades do ambiente de suprir as necessidades de futuras gerações.

Pode-se dizer que o conceito de sustentabilidade considera a conciliação do crescimento econômico com a manutenção do meio ambiente, além de focar a justiça social e o desenvolvimento humano, tendo como base uma distribuição e utilização equilibrada de recursos em um sistema de igualdade social (BANERJEE, 2002).

O conceito de sustentabilidade corporativa induz a um novo modelo de gestão de negócios que leva em conta, no processo de tomada de decisão, além da dimensão econômica, as dimensões social e ambiental. Desse modo, a sustentabilidade pode ser analisada e caracterizada a partir de diferentes dimensões. No entanto, Fialho et al. (2008, p. 106) afirmam que "apesar de apresentarem similaridades nas áreas prioritárias identificadas, são interdependentes, ou seja, não é possível isolá-las".

No âmbito das organizações em geral, destaca-se o tripé da sustentabilidade, ou triple bottom line, na expressão original cunhada por John Elkington (1997), que se tornou popular no ambiente empresarial com o livro "Cannibals with forks". Para ele, o modelo de negócio tradicional, que considerava somente os fatores econômicos (lucro) na avaliação de uma empresa, expande-se para um novo modelo ao contemplar o desempenho ambiental (planeta), social (pessoas) e financeiro da empresa. Dessa forma, Elkington (1997) sugere que as empresas avaliem o sucesso não só com base no desempenho financeiro (geralmente expresso em termos de lucro, retorno sobre o investimento ou valor para os acionistas), mas também sob o ponto de vista de seu impacto sobre a economia mais ampla, sobre o meio ambiente e sobre a sociedade em que atuam.

Para Werbach (2010), a sustentabilidade tem quatro componentes/dimensões igualmente importantes, ao invés dos três apresentados no triple bottom line: são as dimensões econômica, social, ambiental e cultural. Esta última se refere às ações por meio das quais as comunidades manifestam sua identidade e cultivam tradições que passam de geração em geração.

Percebe-se, assim, que o conceito de sustentabilidade corporativa induz a um novo modelo de gestão de negócios que leva em conta, no processo de tomada de decisão, além da dimensão econômica, as dimensões social e ambiental. Tal conceito parte da constatação de que as atividades produtivas ou prestadoras de serviços geram externalidades positivas e negativas. 
São exemplos de externalidades positivas o desenvolvimento econômico e social de determinada região a partir da instalação de uma indústria no local ou, ainda, a melhoria da qualidade de vida de comunidades quando contempladas com oportunidades de emprego. Ao contrário, são exemplos de externalidades negativas a poluição do ar, a emissão de gases de efeito estufa, o aumento de ruído ou, ainda, o crescimento desordenado de determinado local em função de uma interferência não planejada por parte de uma atividade produtiva (ZYLBERSZTAJN e LINS, 2010).

Nesta seção, buscou-se apresentar as origens, os conceitos e as dimensões da sustentabilidade no contexto empresarial. A seguir, aborda-se a técnica de análise de conteúdo que foi utilizada para análise dos artigos selecionados.

\section{ANÁLISE DE CONTEÚDO - DEFINIÇÕES, CARACTERÍS- TICAS E LIMITAÇÕES}

A análise de conteúdo tem sido desenvolvida desde o início do século XX. Sobre esse tema, a autora Laurence Bardin é considerada referência. Para ela, a análise de conteúdo se define como:

um conjunto de técnicas de análise das comunicações visando obter, por procedimentos sistemáticos e objetivos de descrição do conteúdo das mensagens, indicadores (quantitativos ou não) que permitam a inferência de conhecimentos relativos às condições de produção/recepção (variáveis inferidas) destas mensagens (BARDIN, 1977, p.42).

A análise de conteúdo tem como principais características o fato de que (BARDIN, 1977; BAUER, 2002; VERGARA, 2005): (a) pode ser utilizada tanto para fins exploratórios, isto é, de descoberta, quanto de verificação, confirmando ou não hipóteses ou suposições preestabelecidas; (b) exige categorias exaustivas, mutuamente exclusivas, objetivas e pertinentes; (c) pode tratar grandes quantidades de dados, bem como armazená-las com o auxílio de programas de computador (a interpretação dos dados, contudo, cabe ao pesquisador); e (d) com ela, corre-se o risco, quando se detém nas frequências, de deixar passar o que está ausente ou é raro, porém relevante para a análise do objeto em estudo.

Vale ressaltar que a análise de conteúdo admite tanto abordagens quantitativas quanto qualitativas ou, ainda, ambas (BARDIN, 1977), apesar de ter sido concebida com base na quantificação. Cabe destacar que, por mais que vários autores abordem a análise de conteúdo, até mesmo utilizando conceitos diferenciados e diferentes terminologias para as diversas etapas da técnica, neste estudo toma-se como base a conceituação de Bardin (1977; 2010), bem como as etapas da técnica apresentadas por esta autora. Tal opção se deve ao fato de que esta autora é a mais citada em pesquisas que adotam a análise de conteúdo como técnica de análise de dados.

Conforme Bardin (1977), a análise de conteúdo compreende três etapas básicas: (a) pré-análise; (b) exploração do material; e (c) tratamento dos dados, inferência e interpretação. A pré-análise refere-se à fase em que se organiza o material a ser analisado com o objetivo de torná-lo operacional, sistematizando as ideias iniciais. Trata-se da organização dos materiais em quatro etapas: (a) leitura flutuante, que é o estabelecimento de contato com os documentos da coleta de dados, ou seja, é o momento em que se começa a conhecer o texto; (b) escolha dos documentos, que consiste na demarcação do que será analisado; (c) formulação das hipóteses e dos objetivos; (d) referenciação dos índices, que envolve a determinação de indicadores por meio de recortes de texto nos documentos de análise (BARDIN, 1977).

A segunda etapa, denominada exploração do material, consiste na definição de categorias, isto é, em sistemas de codificação e na identificação das unidades de registro e das unidades 
de contexto nos documentos. Essa etapa de exploração de material é importante porque vai possibilitar ou não a riqueza das interpretações e inferências. Essa é a fase da descrição analítica, a qual diz respeito ao corpus, ou seja, a qualquer material textual coletado, submetido a um estudo aprofundado, orientado pelas hipóteses e referências teóricas. Dessa forma, a codificação, a classificação e a categorização são processos básicos nessa fase (BARDIN, 1977).

A terceira etapa refere-se ao tratamento dos resultados, à inferência e à interpretação. É destinada ao tratamento dos resultados e à condensação e ao destaque das informações para análise, culminando nas interpretações inferenciais. Trata-se, também, do momento da intuição e da análise reflexiva e crítica.

Categorizar implica isolar elementos para, em seguida, agrupá-los. Um conjunto de categorias boas deve apresentar as seguintes qualidades (BARDIN, 2010): (a) ser mutuamente exclusivas, - cada elemento só poderá ser incluído em uma única categoria; (b) ter homogeneidade - o princípio da exclusão mútua depende da homogeneidade das categorias, de modo que, um único princípio de classificação deve governar a sua organização; (c) apresentar pertinência - uma categoria é considerada pertinente quando está adaptada ao material de análise escolhido e quando pertence ao quadro teórico definido, ou seja, é adequada ao objetivo da pesquisa; (d) possuir objetividade e fidelidade - poder ser definido de maneira precisa, a fim de evitar dúvidas na distribuição dos elementos; (e) produtividade - um conjunto de categorias é produtivo se fornece elementos férteis, tais como índices de inferências, novas hipóteses, pressupostos e/ou proposições.

Vale ressaltar que toda técnica de análise apresenta certas limitações. Flick (2005, p. 294) destaca "que muitas vezes a falta de profundidade nas análises se constitui no uso de paráfrases, utilizadas não apenas para explicar o texto básico, mas também para substituí-lo, sobretudo na síntese da análise de conteúdo". De outro lado, Thompson (1995, p. 409) chama atenção para o fato de "o pesquisador não ser neutro", referindo-se ao "mito do receptor passivo". Dessa forma, a inferência do pesquisador, a qual se faz necessária, não é totalmente neutra; no entanto, ele deve procurar interferir o mínimo possível.

Outra limitação da análise de conteúdo, destacada por Godoy (1995), é o fato de ter privilegiado as formas de comunicação oral e escrita, excluindo, por vezes, outros meios de comunicação, também significativos e que podem fazer total diferença dependendo da temática em análise. Nesse sentido, mais uma vez, a criatividade e a flexibilidade fazem-se necessárias (DENZIN; LINCOLN, 2008; FLICK, 2005) para não limitar a pesquisa.

Por fim, cabe salientar que a análise de conteúdo possibilita a utilização de diferentes estratégias de análise no seu desenvolvimento metodológico; mas, ao mesmo tempo, apresenta limites e falácias. Dessa forma, a busca por critérios de validade e confiabilidade constitui-se em um caminho para a superação das limitações, inerentes ou não à própria técnica.

\section{MÉTODO DE PESQUISA}

Para este estudo, com o propósito de uma melhor sistematização, projetou-se o levantamento dos dados em três etapas. Na primeira etapa, selecionaram-se os artigos em Journals internacionais disponibilizados na base $E B S C O$, em biblioteca digital na Web, que apresentavam no título, no resumo ou nas palavras-chave as expressões: "sustentabilidade" e "desenvolvimento sustentável". Os 58 artigos encontrados foram publicados em revistas internacionais com fator de impacto relevante, tais como: International Journal of Business and Management, Journal of the Academy of Marketing Science, Harvard Business Review, Strategic Management Journal, Clean Technologies and Environmental Policy Journal, Sustainability: Science, Practice \& Policy, Business Ethics Quartely, The Academic 
of Management Review, New York Times Magazine, Academy of Management Review, Journal of Business Systems, Governance and Ethics e Journal Sustainability Science.

Na segunda etapa, procedeu-se à leitura integral dos artigos pré-selecionados na fase inicial. Nesta fase, foram identificados e descartados 38 artigos, que tratavam das origens, do histórico e dos conceitos do tema sustentabilidade. A decisão de excluir tais artigos fundamentou-se na ideia de que o objetivo deste estudo consiste em averiguar as contribuições e os avanços que esses artigos trouxeram para esse campo científico, bem como as articulações com teorias da administração, o que não ocorreu nesses casos.

Na terceira e última etapa, os textos resultantes da pré-seleção, 20 artigos, foram lidos novamente integralmente e submetidos aos critérios da análise de conteúdo qualitativa (BARDIN, 1977; BAUER, 2002; FLICK, 2005; VERGARA, 2005). Na sequência, por meio da análise de conteúdo, elaborou-se um quadro para catalogação dos artigos de modo a facilitar a busca das informações, sempre que necessário. Esse documento reuniu, de forma resumida, todo o conteúdo necessário para atender ao objetivo proposto. Vale ressaltar que o período de coleta e análise dos dados foi realizado entre abril e julho de 2012.

No Apêndice A, apresentam-se, em ordem alfabética, os vinte artigos selecionados ordenados. Para cada um deles, ressalta-se o objetivo, o método utilizado, as principais contribuições, as categorias identificadas, as lacunas ou as sugestões de estudos. Vale ressaltar que neste artigo não se pretende realizar um estudo com uma amostra representativa, mas sim analisar com profundidade os artigos selecionados, aplicando a técnica de análise de conteúdo qualitativa.

\section{ANÁLISE DOS RESULTADOS}

$\mathrm{Na}$ introdução, foram apresentadas as seguintes questões que sustentam o objetivo geral deste artigo: 1) Como os autores vêm trabalhando o tema da sustentabilidade em publicações internacionais? 2) Quais são as principais teorias da administração a que o tema é relacionado? 3) Quais são as categorias que emergem dessas pesquisas? 4) Quais são as contribuições e os avanços que esses estudos trouxeram para o campo científico em questão? 5) Quais são as lacunas que esses artigos apresentam? 6) Como a técnica de análise de conteúdo qualitativa pode facilitar a busca de respostas para as questões apresentadas?

Em relação às duas primeiras perguntas, constatou-se que o tema sustentabilidade está associado às áreas de estratégias organizacionais, marketing e operações no campo das ciências sociais. Geralmente, as pesquisas nestas áreas adotam a abordagem qualitativa para resolução do problema de pesquisa, buscando entender como determinado fenômeno ocorre. Isso pode ser observado nos 20 artigos pesquisados, dos quais 15 (75\%) artigos utilizaram a abordagem qualitativa (ensaios teóricos e/ou estudos de casos) e cinco (25\%) utilizaram a abordagem quantitativa para o problema de pesquisa.

Para Shah e Corley (2006), o método qualitativo é considerado poderoso para construir novas teorias ou refinar as teorias existentes, além de ser um conjunto de coleta de dados e técnicas de análise que pode ser usado para fornecer descrições e testar teorias. Desse modo, o método qualitativo permite que o investigador descubra novas variáveis e relações; revele e compreenda processos complexos; e ilustre a influência do contexto social.

Para identificar as categorias sobre o tema sustentabilidade, utilizaram-se as três etapas básicas da análise de conteúdo de Bardin (1977): (a) pré-análise; (b) exploração do material; (c) e tratamento dos dados, inferência e interpretação. Na etapa de pré-análise, fez-se a busca dos artigos em publicações internacionais na base EBSCO e a leitura flutuante de cada artigo, ou seja, o 
estabelecimento de contato com o documento da coleta de dados para se conhecer os textos. $\mathrm{Na}$ sequência, realizou-se a demarcação do que seria analisado nos artigos selecionados e, por fim, fez-se a referenciação dos índices. Nesta etapa, procedeu-se à marcação dos objetivos, métodos, principais contribuições, lacunas e/ou sugestões para novas pesquisas de cada artigo (APÊNDICE A).

A segunda etapa, denominada de exploração de material, consiste na exploração do material selecionado com a definição de categorias, isto é, de sistemas de codificação e da identificação das unidades de registro e das unidades de contexto nos documentos. Segundo Bardin (1977), esta etapa é importante porque vai possibilitar ou não a riqueza das interpretações e inferências. Nesta etapa, foram explorados e analisados os itens demarcados na etapa de pré -análise e elaborou-se o quadro 1 que apresenta os autores identificados, o foco do estudo das publicações e as categorias que emergiram desses artigos.

\begin{tabular}{|c|c|c|}
\hline Autores & $\begin{array}{l}\text { Foco do estudo } \\
\text { sobre sustentabilidade }\end{array}$ & Categorias \\
\hline Bansal (2005) & $\begin{array}{l}\text { Os determinantes para o desenvol- } \\
\text { vimento da sustentabilidade corpo- } \\
\text { rativa. }\end{array}$ & $\begin{array}{l}\text { Desenvolvimento da sustentabilidade corpora } \\
\text { tiva: experiência internacional, capacidades de } \\
\text { gerenciamento de capital, multas e penalida- } \\
\text { des e atenção da mídia. }\end{array}$ \\
\hline Carrol (1979) & Desempenho social das empresas. & $\begin{array}{l}\text { Responsabilidade social total = responsabilida } \\
\text { de econômica, legal, ética e discricionária. }\end{array}$ \\
\hline $\begin{array}{l}\text { Chabowski, et al } \\
\text { (2011) }\end{array}$ & Sustentabilidade e marketing. & $\begin{array}{l}\text { Recursos corporativos e desempenho ambiental } \\
\text { teoria do stakeholder e desempenho financeiro, } \\
\text { teoria do stakeholder e desempenho social. }\end{array}$ \\
\hline $\begin{array}{l}\text { Crittenden, et al } \\
\text { (2011) }\end{array}$ & $\begin{array}{l}\text { Sustentabilidade e orientação para } \\
\text { o mercado. }\end{array}$ & $\begin{array}{l}\text { DNA (ideologia central, capacidades dinâmicas } \\
\text { e engajamento da sociedade), envolvimento } \\
\text { dos stakeholders, desempenho da gestão (per } \\
\text { formance social e financeira). }\end{array}$ \\
\hline Friedman (1970) & $\begin{array}{l}\text { Responsabilidade social nos negó- } \\
\text { cios. }\end{array}$ & $\begin{array}{l}\text { Ética, responsabilidade social do indivíduo e } \\
\text { responsabilidade social da empresa. }\end{array}$ \\
\hline $\begin{array}{l}\text { Gladwin, et al } \\
\text { (1995) }\end{array}$ & Os paradigmas e a sustentabilidade. & $\begin{array}{l}\text { Desenvolvimento sustentável, paradigmas e com } \\
\text { ponentes do desenvolvimento sustentável (inclusão, } \\
\text { conectividade, equidade, prudência e segurança). }\end{array}$ \\
\hline Higgins (2011) & Responsabilidade social corporativa. & $\begin{array}{l}\text { Responsabilidade social corporativa, mudança } \\
\text { organizacional. }\end{array}$ \\
\hline Hult (2011) & $\begin{array}{l}\text { Sustentabilidade e orientação para } \\
\text { o mercado. }\end{array}$ & $\begin{array}{l}\text { Forças econômicas, do ambiente e sociais } \\
\text { orientação de mercado e stakeholders. }\end{array}$ \\
\hline $\begin{array}{l}\text { Kajikawa, et al } \\
(2007)\end{array}$ & $\begin{array}{l}\begin{array}{l}\text { Áreas e subáreas da ciência da sus- } \\
\text { tentabilidade. }\end{array} \\
\end{array}$ & Ciência da sustentabilidade, áreas e subáreas. \\
\hline $\begin{array}{l}\text { Lempert; Nguyen } \\
\text { (2011) }\end{array}$ & $\begin{array}{l}\text { Fatores que motivam os atores para } \\
\text { prática da sustentabilidade. }\end{array}$ & $\begin{array}{l}\text { População versus consumo e recursos versus } \\
\text { produtividade. }\end{array}$ \\
\hline $\begin{array}{l}\text { Martins, et al } \\
(2006)\end{array}$ & Educação para sustentabilidade. & $\begin{array}{l}\text { Nível de educação básico, universitário e orga- } \\
\text { nizacional e educação para toda vida. }\end{array}$ \\
\hline $\begin{array}{l}\text { Murillo-Luna, et } \\
\text { al (2008) }\end{array}$ & Sustentabilidade e stakeholders. & $\begin{array}{l}\text { Padrões de responsabilidade ambiental, am } \\
\text { biente de proatividade e influência dos stake } \\
\text { holders. }\end{array}$ \\
\hline $\begin{array}{l}\text { Newell; Moore } \\
(2010)\end{array}$ & $\begin{array}{l}\text { Sustentabilidade e pequenas em- } \\
\text { presas. }\end{array}$ & $\begin{array}{l}\text { Governança corporativa, diferenças entre gera } \\
\text { ções, logística, contabilidade, tecnologia e am } \\
\text { biente. }\end{array}$ \\
\hline $\begin{array}{l}\text { Norman; Macdo- } \\
\text { nald (2004) }\end{array}$ & Triple bottom line. & $\begin{array}{l}\text { Mensuração, agregação, convergência, obriga- } \\
\text { ção social e transparência. }\end{array}$ \\
\hline $\begin{array}{l}\text { Porter; Kramer } \\
(2006)\end{array}$ & $\begin{array}{l}\text { Responsabilidade social corporativa } \\
\text { e vantagem competitiva. }\end{array}$ & $\begin{array}{l}\text { Mensuração, comunicação e impacto das práti } \\
\text { cas sociais na cadeia de valor. }\end{array}$ \\
\hline $\begin{array}{l}\text { Porter; Vander } \\
\text { Der Linde (1995) }\end{array}$ & $\begin{array}{l}\text { Trade-off entre meio-ambiente e } \\
\text { economia. }\end{array}$ & $\begin{array}{l}\text { Produtividade, inovação, leis ambientais e com - } \\
\text { petitividade. }\end{array}$ \\
\hline
\end{tabular}




\begin{tabular}{|l|l|l|}
\hline Yaacob (2010) & Empreendedores verdes. & $\begin{array}{l}\text { Empreendedor verde, itens recicláveis e negó- } \\
\text { cio verde. }\end{array}$ \\
\hline Yilmaz (2008) & Responsabilidade social. & $\begin{array}{l}\text { Sustentabilidade corporativa e responsabilida- } \\
\text { de social corporativa. }\end{array}$ \\
\hline Zilay (2006) & Educação e sustentabilidade. & $\begin{array}{l}\text { Educação no nível superior, currículo e desen- } \\
\text { volvimento sustentável. }\end{array}$ \\
\hline $\begin{array}{l}\text { Zhang; Tian } \\
\text { (2008) }\end{array}$ & $\begin{array}{l}\text { Manufatura verde e responsabilida- } \\
\text { de social. }\end{array}$ & $\begin{array}{l}\text { Manufatura verde e responsabilidade social } \\
\text { corporativa. }\end{array}$ \\
\hline
\end{tabular}

Quadro 1: Relação de autores, foco da pesquisa e categorias identificadas.

Fonte: elaborada pela autora (2012).

Para Bardin (2010), classificar elementos em categorias impõe a investigação do que cada um deles tem em comum com os outros. Logo, o que permite seu agrupamento é a parte comum entre eles. Neste estudo, para identificar as categorias, buscou-se levar em consideração os itens que conferem uma boa qualidade ao conjunto de categorias: exclusão mútua, homogeneidade, pertinência, objetividade e fidelidade e produtividade.

A terceira etapa refere-se ao tratamento dos resultados, à inferência e à interpretação. Destina-se ao tratamento dos resultados, à condensação e ao destaque das informações para análise, bem como às interpretações inferenciais, sendo o momento da intuição e da análise reflexiva e crítica (BARDIN, 1977). Analisando o quadro 1, pode-se perceber que os artigos apresentam categorias diversas conforme o objetivo e a área de estudo da pesquisa. Dentre os artigos selecionados, observa-se que a dimensão social da sustentabilidade foi destaque (CARROL, 1979; FRIEDMAN, 1970; HIGGINS, 2011; PORTER, KRAMER, 2006; YILMAZ, 2008). No entanto, a maioria apresenta o alinhamento das três dimensões - econômica, social e ambiental - como característica principal da sustentabilidade (CHABOWSKI et al.; CRITTENDEN et al., 2011; HULT, 2001; MURILLO-LUNA et al, 2008; NORMAN, MACDONALD, 2004; ZHANG, TIAN, 2008). Embora exista um debate acerca da definição do termo sustentabilidade corporativa, este pode ser entendido, de modo geral, como as atividades empresariais que demonstram a inclusão de aspectos sociais e ambientais na operação do negócio e nas interações com stakeholders. Nesse sentido, a maioria dos autores enfatiza a elaboração de estratégias voltadas para essas três dimensões no contexto empresarial, no intuito de buscar um equilíbrio.

Tal fato corrobora a abordagem de Elkinton (1997), que elaborou o tripé da sustentabilidade, ou seja, o triple bottom line, o qual se tornou popular no ambiente empresarial com o livro Cannibals with forks. Para o autor, o modelo de negócio tradicional, que considerava somente os fatores econômicos (lucro) na avaliação de uma empresa, expande-se para um novo modelo ao contemplar a performance ambiental (planeta), social (pessoas) e financeira da empresa.

Também se evidenciou a categoria da mensuração de resultados, reforçando que os impactos dos investimentos em sustentabilidade devem ser avaliados considerando as dimensões econômica, social e ambiental (LEMPERT, NGUYEN, 2011; MURILLO-LUNA et al., 2008; NORMAN, MACDONALD, 2004; PORTER, KRAMER, 2006; PORTER, VANDER DER LINDE, 1995). Em síntese, foram identificas as seguintes categorias principais: (a) dimensão social/responsabilidade social; (b) alinhamento das três dimensões da sustentabilidade - econômica, social e ambiental; (c) mensuração dos resultados das dimensões da sustentabilidade; e (d) relacionamento com os stakeholders.

Em relação às contribuições e aos avanços que os artigos trouxeram para esse campo científico, verificou-se a apresentação de modelos ou frameworks teóricos centrados em paradigmas da sustentabilidade e na inserção do tema no ensino e na educação (GLADWIN et al., 1995; KAJIKAWA et al., 2007; MARTINS et al., 2006; ZILAY, 2006). Outros autores buscaram identificar os fatores determinantes ou elementos que influenciam o desenvolvimento da sustentabilidade corporativa 
ou de alguma dimensão específica da sustentabilidade, como a social ou ambiental (BANSAL, 2005; CARROL, 1979; FRIEDMAN, 1979; HIGGINS, 2011; NORMAN, MACDONALD, 2004; YAACOB, 2010; YILMAZ, 2008; ZHANG, TIAN, 2008). Alguns estudos apresentaram a importância do alinhamento entre estratégias organizacionais com a orientação para o mercado, as operações, os interesses dos stakeholders e a governança corporativa para se obter vantagem competitiva (CHABOWSKI et al., 2011; CRITTENDEN et al., 2011; HULT, 2011; LEMPERT, NGUYEN, 2011; MURILLO-LUNA et al., 2008; NEWELL, MOORE, 2010; PORTER, KRAMER, 2006; PORTER, VANDER DER LINDE, 1995).

Vale ressaltar que algumas teorias já consolidadas foram associadas com a teoria da sustentabilidade, visando verificar as contribuições dessas teorias para facilitar ou dificultar as práticas de sustentabilidade. As teorias mais citadas foram: a teoria dos recursos e capacidades (RBV), a teoria institucional, a teoria dos stakeholders, a teoria da orientação de mercado do marketing, a teoria da cadeia produtiva e a vantagem competitiva.

Quanto às lacunas encontradas a partir da análise de conteúdos dos artigos, observaram-se os seguintes assuntos: integração da teoria institucional com a teoria baseada em recursos para o desenvolvimento da sustentabilidade corporativa; construção e testagem de um modelo de mensuração de resultados das três dimensões do triple bottom line conforme padrões internacionais de práticas sustentáveis; perspectiva da teoria baseada em recursos e capacidades dinâmicas para o desenvolvimento da sustentabilidade corporativa; estudo da relação da empresa com seus stakeholders para consolidação da estratégia de sustentabilidade; integração entre os níveis de educação para aproximar o tema sustentabilidade dos currículos de ensino.

Para Weick (1995), nos estudos organizacionais, raras são as teorias plenas. Normalmente, o que se chama de teoria são aproximações. O autor acredita que partes de artigos, como referências, dados empíricos, variáveis e hipóteses, podem eventualmente ser consideradas teoria. Isso ocorre porque o trabalho teórico pode assumir múltiplas formas; a própria teoria é um continuum; e a maioria das teorias, quando expressas verbalmente, deixam tácitas partes relevantes do insight original. Dessa forma, é difícil julgar se estamos ou não diante de uma teoria olhando apenas para o produto; é preciso examinar o processo de teorização.

Para DiMaggio (1995), há mais de um tipo de boa teoria: (a) teorias que tratam de regras - generalizações que descrevem o mundo; (b) teorias como iluminação - complexas, não familiares, ricas em paradoxos e mais baseadas na intuição; e (c) teorias como narrativas - descrição de um processo social, com ênfase nos testes empíricos de plausibilidade e atenção cuidadosa com o escopo da explicação. Já Sutton e Staw (2003) consideram teoria apenas a teoria como narrativa.

Nos artigos analisados, é possível identificar dois tipos de teorias: teorias que tratam de regras fazendo generalizações que descrevem o mundo, pois se tentou estabelecer um mapa único sobre as dimensões da sustentabilidade; e teorias como narrativas que descrevem um processo social com ênfase em testes empíricos e com escopo definido.

\section{CONSIDERAÇÕES FINAIS}

Este estudo objetivou identificar artigos relacionados ao tema da sustentabilidade em publicações internacionais e analisar as categorias que emergem desses artigos por meio do uso da técnica de análise de conteúdo qualitativa, buscando identificar as principais abordagens, as contribuições, as lacunas teóricas e as sugestões para novos estudos. Para isso, foram selecionados 20 artigos, analisados sob a perspectiva da análise de conteúdo qualitativa.

Após a análise dos artigos identificados, percebeu-se que o tema da sustentabilidade está relacionado às temáticas: estratégia, marketing, operação, empreendedorismo e educação. 
Verificou-se, também, que o tema, apesar de estar sendo bastante discutido em pesquisas publicadas em revistas internacionais, ainda está em amadurecimento na sociedade e nas organizações. Vale ressaltar que esse tema suscita várias críticas devido ao seu amplo conteúdo e à ausência de foco, podendo ser interpretado como um novo modelo de desenvolvimento ou apenas um redesenho do capitalismo.

Quanto ao ato de colocar em prática a sustentabilidade, algumas organizações se limitam a cumprir o que determina a lei, enquanto outras vão um pouco além, pressionadas por demandas do consumidor ou de um cliente-chave. Há, no entanto, aquelas que apresentam um grau maior de conscientização, o que possibilita alinhar as questões relacionadas à sustentabilidade com a estratégia do negócio.

Com o emprego da técnica de análise de conteúdo qualitativa, foi possível identificar sugestões de pesquisas para novos estudos sobre o tema, tais como: integração da teoria institucional com a teoria baseada em recursos para o desenvolvimento da sustentabilidade corporativa; construção e testagem de um modelo de mensuração de resultados das três dimensões do triple bottom line conforme padrões internacionais de práticas sustentáveis; perspectiva da teoria baseada em recursos e capacidades dinâmicas para o desenvolvimento da sustentabilidade corporativa; estudo da relação da empresa com seus stakeholders para consolidação da estratégia de sustentabilidade; e integração entre os níveis de educação para aproximar a sustentabilidade dos currículos de ensino.

Sugere-se, ainda, para novos estudos, a comparação de produções nacionais com produções internacionais sobre sustentabilidade com o objetivo de verificar e comparar as categorias que emergem desses estudos, buscando novas lacunas teóricas. Como limitações desta pesquisa, pontua-se o número de artigos selecionados, que é pequeno se comparado à quantidade de publicações sobre o tema. Este artigo constitui, portanto, um trabalho que não tem a pretensão de ser conclusivo, mas provocativo, buscando instigar o leitor na construção de novas possibilidades que envolvem o tema e aprofundar algumas reflexões.

\section{REFERÊNCIAS}

BANERJEE, Subhabrata B. Organisational strategies for sustainable development: developing a research agenda for the new Millennium. Australian Journal of Management, V. 27, Special Issue, 2002.

BARDIN, L. Análise de conteúdo. Lisboa: Edições 70, 1977.

BARDIN, L. Análise de conteúdo. Lisboa: Edições 70, 2010.

BANSAL, P. Envolving sustainably: a longitudinal study of corporate sustainable development. Strategic Management Journal, v.26, n.3, PP.197-218, 2005.

BAUER, M. W. Análise de conteúdo clássica: uma revisão. In: BAUER, M.W.; GASKELL, G. Pesquisa qualitative com texto, imagem e som: um manual prático. Petrópolis: Vozes, 2002.

CARROL, Archie B. A three-dimensional conceptual model of corporate performance. The Academy Of Management Review, v.14, n.4, Oct., 1979, pp. 497-505.

CHABOWSKI, Brian R.; MENA, Jeannette; PADRON-GONZALES, Tracy. The structure of sustainability research in marketing, 1958 2008: a basis for future research opportunities. Journal of the Academy of Marketing Science, n.39, pp. 55-70, 2011.

COMISSÃO MUNDIAL SOBRE O MEIO AMBIENTE E DESENVOLVIMENTO. Nosso 
Futuro Comum. 2 ed. Rio de Janeiro: Editora da Fundação Getúlio Vargas, 430 p., 1991.

CRITTENDEN, V.L.; CRITTENDEN, W.F.; FERREL, L.K.; PINNEY, C.C. Market-oriented sustainability: a conceptual framework and propositions. Journal of the Academy of Marketing Science, 39:71-85, 2011.

DENZIN, N. K., LINCOLN, Y. S. Collecting and interpreting qualitative materials. Los Angeles: Sage, 2008.

DIMAGGIO, P. Comments on "What theory is not". Administrative Science Quarterly, v. 40, n. 3, p. 391-397, 1995.

ELKINGTON, John. Canibals with forks: the triple bottom line of $21^{\text {st }}$ century business. Capstone Publishing, Oxford, 1997.

FIALHO, Francisco Antonio Pereira et al. Gestão da sustentabilidade na era do conhecimento. Florianópolis: Visual books, 2008.

FLICK, U. Uma introdução à pesquisa qualitativa. 2 ed. Porto Alegre: Bookman, 2005.

FRIEDMAN, Milton. The social responsibility of business is to increase its profits. New York Times Magazine, v.13, n.1970, pp. 32-33, 1970.

GLADWIN, T.N; KENNELLY, J.; KRAUSE, T.S. Shifting paradigms for sustainable development: implications for management theory and research. Academy of Management Review, v.20, n.4, pp. 874-907, 1995.

GODOY, A. S. Introdução à pesquisa qualitativa e suas possibilidades. Revista de Administração de Empresas, 35(2), 1995, PP.57-63.

HAWKEN, P. The Ecology of Commerce. Harper Collins, 1993.

HIGGINS, Colin. Is a responsive business also a responsible business! Journal of Business Systems, Governance and Ethics, v.5, n.3, pp. 23-32, 2011.
HULT, G. Tomas M. Market-focused sustainability: market orientation plus! Journal of the Academy of Marketing Science, n.39, pp. 1-6, 2011.

KAJIKAWA, Yuya; OHNO, Junko; TAKEDA, Yoshiyuki; MATSUSHIMA, Katsumori; KOMIYAMA, Hiroshi. Creating an academic landscape of sustainability science: an analysis of the citation network. Journal Sustainability Science, 2: 221-231, 2007.

LEMPERT, David; NGUYEN, Hue. The global prisoners'dilemma of unsustainability: why sustainable development cannot be achieved without resource security and eliminating the legacies of colonialism. Sustainability: Science, Practice \& Policy, v.7, n.1, pp16-30, 2011.

MARTINS, A.A.; MATA, T.M.; COSTA, C.A.V. Education for sustainability: challenges and trends. Clean Technologies and Environmental Policity Journal, 8:31-37, 2006.

MURILLO-LUNA， J.L.; GARCÉS-AYERBE， C.; RIVERA-TORRES, P. Why do patterns of environmental response differ? A stakeholders pressure approach. Strategic Management Journal, v.29, n.11, pp. 1225-1240, 2008.

NEWELL, Christopher J.; MOORE, Walter. Creating small business sustainability awareness. International Journal of Business and Management, v.5, n.9, PP. 19-25, 2010.

NORMAN, Wayne; MACDONALD, Chris. Getting to the bottom of "Triple Bottom Line". Business Ethics Quarterly, v.4, n.2, pp. 243262, 2004.

ONU - ORGANIZAÇÃO DAS NAÇÕES UNIDAS. Direitos Humanos. 2006. Disponível em: http://portal.mj.gov.br/sedh/biblioteca/ livro_percepcoes/percepcoes.pdf. Acesso em: março de 2013.

ONU - ORGANIZAÇÃO DAS NAÇÕES UNIDAS. Objetivos de Milênio. 2000. Disponível em: http://www.objetivosdomilenio.org.br/. Acesso em: março de 2013. 
PORTER, M.E; KRAMER, M.R. Strategy and society: the link between competitive advantage and corporate social responsibility. Harvard Business Review, v.84, n.12, PP. 78-92, 2006.

PORTER, M.E; VANDER DER LINDE, C. Green and competitive: ending the stalemate. Harvard Business Review, v.73, n.5, pp. 120133, 1995.

SACHS, Ignacy. Estratégias de Transição para o Século XXI: desenvolvimento e meio ambiente. São Paulo: Studio Nobel e Fundação de Desenvolvimento Administrativo (Fundap), p.24-27, 1993.

REDCLIFT, M. Sustainable development: exploring the contradictions. London: Metheun, 1987.

SAVITZ, Andrew W.; WEBER, Karl. A empresa sustentável: o verdadeiro sucesso é o lucro com responsabilidade social e ambiental. Rio de Janeiro: Elsevier, 2007.

SHAH, Sonali K.; CORLEY, Kevin. Building Better Theory by Bridging the QuantitativeQualitative Divide. Journal Of Management Studies, 43:8, December, 2006.

SUTTON, R. I.; STAW, B. M. O que não é teoria. Revista de Administração de Empresas, v. 43, n. 3, p. 74-84, jul/set, 2003.

THOMPSON, J. B. Ideologia e cultura moderna: teoria social crítica na era dos meios de comunicação de massa. Rio de Janeiro: Vozes, 1995.

UNCED. UNITED NATIONS CONFERENCE ON SUSTAINABLE DEVELOPMENT. Rio+20. June 2012. http://www.uncsd2012.org/rio20/ about.html. Acesso em março de 2013.

UNCED. CONFERENCE ON ENVIRONMENT AND DEVELOPMENT. Rio 92. 3-12 June 1992. http:// www.un.org/geninfo/bp/enviro.html. Acesso em: março de 2013.

VERGARA, S.C. Métodos de pesquisa em administração. São Paulo: Atlas, 2005.

WCED - World Commission on Environment and Development. Our common future. Oxford: Oxford University Press, 1987.

WEICK, K. What theory is not, theorizing is. Administrative Science Quarterly, v. 40, n. 3, p. 385-390, 1995.

WERBACH, Adam. Estratégia para sustentabilidade: uma nova forma de planejar sua estratégia empresarial. Rio de Janeiro: Elsevier, 2010.

YAACOB, Mohd R. A preliminary study of green micro-entrepreneurs in Kelatan, Malaysia. International Journal of Business and Management, v.5, n.3, pp. 81-88, 2010.

YILMAZ, Ayse K. The corporate social responsibility practice in the Turkish Automotive Distribution Companies. International Journal of Business and Management, v.3, n.6, pp. 139-147, 2008.

ZHANG, Z.; TIAN, X. Necessarity of practicing green manufacturing in iron industry from the point of social responsibility. International Journal of Business and Management, v.3, n.12, pp. 142-145, 2008.

ZILAY, Gyula. Toward sustainability: the role of higher education. Clean Technologies and Environmental Policiy Journal, 8:1-2, 2006.

ZYLBERSZTAJN, David; LINS, Clarissa (Org.). Sustentabilidade e geração de valor: a transição para o século XXI. Rio de Janeiro: Elsevier, 2010. 


\section{APÊNDICE A - Relação dos artigos selecionados e analisados}

1) BANSAL, P. Envolving sustainably: a longitudinal study of corporate sustainable development. Strategic Management Journal, v.26, n.3, PP.197-218, 2005.

Objetivo: operacionalizar o desenvolvimento da sustentabilidade corporativa e examinar os seus determinantes organizacionais.

Método: revisão bibliográfica e análise estatística dos dados.

Principais contribuiç̃ões: os recursos e fatores institucionais influenciam no desenvolvimento da sustentabilidade corporativa.

Categorias identificadas: variável dependente - desenvolvimento da sustentabilidade corporativa; variáveis independentes experiência internacional, capacidades de gerenciamento de capital, folga organizacional, multas e penalidades, mimetismo, atenção da mídia; variáveis de controle - tamanho da empresa e desempenho financeiro.

Lacunas ou sugestões de estudos: integrar a teoria institucional com a teoria baseada em recursos para o desenvolvimento da sustentabilidade corporativa.

2) CARROL, Archie B. A three-dimensional conceptual model of corporate performance. The Academy Of Management Review, v.14, n.4, Oct., 1979, pp. 497-505.

Objetivo: apresentar um modelo conceitual que descreva de forma abrangente os aspectos essenciais do desempenho social das empresas.

Método: revisão bibliográfica, constituindo-se em um ensaio teórico.

Principais contribuiç̃os: apresentação dos elementos que devem estar presentes na responsabilidade social corporativa, incluindo a filosofia da organização para responder socialmente as diferentes visões ou os caminhos do significado da responsabilidade social.

Categorias identificadas: responsabilidade social total = responsabilidade econômica, legal, ética e discricionária.

Lacunas ou sugestões de estudos: apresenta um modelo, porém não está clara a sua aplicação.

3) CHABOWSKI, Brian R.; MENA, Jeannette; PADRON-GONZALES, Tracy. The structure of sustainability research in marketing, 1958 - 2008: a basis for future research opportunities. Journal of the Academy of Marketing Science, n.39, pp. 55-70, 2011.

Objetivo: analisar o progresso dos estudos sobre sustentabilidade em Journals de marketing.

Método: meta-análise de 1320 artigos e análise de cluster dos dados.

Principais contribuições: apresentação de uma estrutura dos principais temas tratados sobre sustentabilidade na década de 1990 e de 2000.

Categorias identificadas: recursos corporativos e desempenho ambiental, teoria do stakeholder e desempenho financeiro, teoria do stakeholder e desempenho social.

Lacunas ou sugestões de estudos: analisar com profundidade frameworks de estudos; examinar as relações entre as capacidades geração de inteligência, disseminação e responsabilidade - para vantagem competitiva sustentável; analisar a perspectiva da teoria baseada em recursos e capacidades da firma para o desenvolvimento das dimensões social e ambiental.

4) CRITTENDEN, V.L.; CRITTENDEN, W.F.; FERREL, L.K.; PINNEY, C.C. Market-oriented sustainability: a conceptual framework and propositions. Journal of the Academy of Marketing Science, 39:71-85, 2011.

Objetivo: validar o construto a fim de justificar a orientação do mercado para sustentabilidade para ampliação da vantagem competitiva.

Método: revisão bibliográfica, constituindo-se em um ensaio teórico.

Principais contribuições: reforçam a ideia de que uma organização, ao incorporar a sustentabilidade na orientação para o mercado, faz o alinhamento estratégico de sustentabilidade com as estratégias de marketing a fim de criar vantagem competitiva.

Categorias identificadas: DNA (ideologia central, capacidades dinâmicas e engajamento da sociedade), envolvimento dos stakeholders e desempenho da gestão (performance social e financeira).

Lacunas ou sugestões de estudos: indicação de novas proposições que podem ser examinadas, buscando relações entre as variáveis do construto apresentado.

5) FRIEDMAN, Milton. The social responsibility of business is to increase its profits. New York Times Magazine, v.13, n.1970, pp. 32-33, 1970.

Objetivo: refletir sobre a responsabilidade social dos negócios.

Método: revisão bibliográfica, constituindo-se em um ensaio teórico. 
Principais contribuições: apresenta as diferenças das responsabilidades dos indivíduos e da empresa na dimensão social e as dificuldades para exercer a responsabilidade social.

Categorias identificadas: ética, responsabilidade social do indivíduo e responsabilidade social da empresa.

Lacunas ou sugestões de estudos: o tema da responsabilidade social empresarial é fraco em termos analíticos e falta rigor nos estudos; as discussões são muito filosóficas.

6) GLADWIN, T.N; KENNELLY, J.; KRAUSE, T.S. Shifting paradigms for sustainable development: implications for management theory and research. Academy of Management Review, v.20, n.4, pp. 874-907, 1995.

Objetivo: examinar os paradigmas do tecnocentrismo convencionais e egocentrismo antiético em razão da incongruência.

Método: revisão bibliográfica, constituindo-se em um ensaio teórico.

Principais contribuições: mostrar as contribuições dos paradigmas para o desenvolvimento sustentável e quando esses paradigmas devem ser rejeitados.

Categorias identificadas: desenvolvimento sustentável, paradigmas e componentes do desenvolvimento sustentável (inclusão, conectividade, equidade, prudência e segurança).

Lacunas ou sugestões de estudos: construir um framework.

7) HIGGINS, Colin. Is a responsive business also a responsible business! Journal of Business Systems, Governance and Ethics, v.5, n.3, pp. 23-32, 2011.

Objetivo: examinar o tema da responsabilidade social corporativa à luz de suas suposições.

Método: revisão bibliográfica, constituindo-se em um ensaio teórico.

Principais contribuições: a responsabilidade social é central na relação entre negócios e sociedade.

Categorias identificadas: responsabilidade social corporativa; mudança organizacional.

Lacunas ou sugestões de estudos: construir um framework.

8) HULT, G. Tomas M. Market-focused sustainability: market orientation plus! Journal of the Academy of Marketing Science, n.39, pp. 1-6, 2011.

Objetivo: revisar as publicações sobre sustentabilidade e verificar a convergência com a literatura de marketing.

Método: revisão bibliográfica, constituindo em um ensaio teórico.

Principais contribuições: uma organização alcança a sustentabilidade, na medida em que, estrategicamente, a orientação de mercado é alinhada às necessidades de produtos e aos desejos dos clientes e aos interesses dos stakeholders preocupados com as questões ambientais, econômicas e sociais.

Categorias identificadas: as forças econômicas, do ambiente e sociais, orientação de mercado e stakeholders.

Lacunas ou sugestões de estudos: aprofundar estudos da relação da empresa com seus stakeholders para consolidação de estratégias de sustentabilidade.

9) KAJIKAWA, Yuya; OHNO, Junko; TAKEDA, Yoshiyuki; MATSUSHIMA, Katsumori; KOMIYAMA, Hiroshi. Creating an academic landscape of sustainability science: an analysis of the citation network. Journal Sustainability Science, 2: 221-231, 2007.

Objetivo: mostrar um panorama sobre a ciência da sustentabilidade, analisando a relação dos artigos publicados em Journals.

Método: análise dos dados por meio do método de análise de clusters.

Principais contribuições: o artigo apresenta em quais ciências e Journals houve mais citações referentes à ciência da sustentabilidade; foram identificados 93 clusters.

Categorias identificadas: ciência da sustentabilidade, áreas e subáreas.

Lacunas ou sugestões de estudos: construir um framework a partir do panorama apresentado.

10) LEMPERT, David; NGUYEN, Hue. The global prisoners'dilemma of unsustainability: why sustainable development cannot be achieved without resource security and eliminating the legacies of colonialism. Sustainability: Science, Practice \& Policy, v.7, n.1, pp16-30, 2011.

Objetivo: verificar os fatores que motivam os atores para o desenvolvimento sustentável.

Método: revisão bibliográfica, constituindo-se em um ensaio teórico.

Principais contribuições: identificação dos medos e das motivações reais dos diferentes atores na prática do desenvolvimento sustentável. 
Categorias identificadas: população $\mathrm{x}$ consumo; recursos $\mathrm{x}$ produtividade.

Lacunas ou sugestões de estudos: ferramentas de medição do desenvolvimento sustentável das organizações apresentam lacunas em relação aos padrões internacionais de práticas sustentáveis.

11) MARTINS, A.A.; MATA, T.M.; COSTA, C.A.V. Education for sustainability: challenges and trends. Clean Technologies and Environmental Policity Journal, 8:31-37, 2006.

Objetivo: refletir sobre o tema educação para sustentabilidade em todos os níveis de educação formal e não formal, incluindo educação básica, universidades, organizações públicas e privadas e o aprendizado para toda vida.

Método: revisão bibliográfica, constituindo-se em um ensaio teórico.

Principais contribuições: 0 artigo apresenta os desafios e as implicações de incorporar efetivamente os conceitos de sustentabilidade e os seus princípios em todos os níveis do sistema de ensino.

Categorias identificadas: nível de educação básico, nível universitário, nível organizacional e nível de educação para toda vida.

Lacunas ou sugestões de estudos: estudar a falta de integração entre os níveis de educação e uma forma de aproximar a educação para sustentabilidade nos currículos de ensino.

12) MURILLO-LUNA, J.L.; GARCÉS-AYERBE, C.; RIVERA-TORRES, P. Why do patterns of environmental response differ? A stakeholders pressure approach. Strategic Management Journal, v.29, n.11, pp. 1225-1240, 2008.

Objetivo: analisar as estratégias ou a forma como as empresas se adaptam para atender as expectativas e exigências ambientais, verificando a influência dos diferentes agentes ou stakeholders na proatividade dessa adaptação.

Método: revisão bibliográfica, análise de 240 empresas com uso de equações estruturais.

Principais contribuições: forneceu uma escala para mensurar o compromisso ambiental das empresas que pode ser usado para avaliar a dimensão social.

Categorias identificadas: padrões de responsabilidade ambiental, ambiente de proatividade e influência dos stakeholders.

Lacunas ou sugestões de estudos: aprofundar estudos sobre o papel dos stakeholders para a sustentabilidade.

13) NEWELL, Christopher J.; MOORE, Walter. Creating small business sustainability awareness. International Journal of Business and Management, v.5, n.9, PP. 19-25, 2010.

Objetivo: despertar a consciência entre os gestores de pequenas empresas sobre a sustentabilidade.

Método: revisão bibliográfica, constituindo-se em um ensaio teórico.

Principais contribuições: mostrar aos empresários de pequenas empresas que estas podem se tornar empresas "verdes".

Categorias identificadas: governança corporativa, diferenças entre gerações, logística, contabilidade, tecnologia e ambiente.

Lacunas ou sugestões de estudos: estudar os processos para a sustentabilidade e a mensuração dos mesmos.

14) NORMAN, Wayne; MACDONALD, Chris. Getting to the bottom of "Triple Bottom Line". Business Ethics Quarterly, v.4, n.2, pp. 243-262, 2004.

Objetivo: examinar criticamente a noção do Triple Bottom Line, verificando as linhas teóricas que defendem o TBL e as que são contrárias a ele.

Método: revisão bibliográfica, constituindo-se em um ensaio teórico.

Principais contribuições: os autores apresentam várias críticas ao uso do Triple Bottom Line (teórica e prática), destacando que a retórica é enganosa e que as empresas se escondem atrás de uma cortina de fumaça em relação às questões do TBL, principalmente na dimensão social, e apresentando indicadores da dimensão social para mensuração.

Categorias identificadas: mensuração, agregação, convergência, obrigação social e transparência.

Lacunas ou sugestões de estudos: na opinião dos autores não é necessário usar a expressão "triple bottom line" (paradigma), mas apenas "bottom line".

15) PORTER, M.E; KRAMER, M.R. Strategy and society: the link between competitive advantage and corporate social responsibility. Harvard Business Review, v.84, n.12, PP. 78-92, 2006.

Objetivo: mostrar o link entre vantagem competitiva e responsabilidade social corporativa.

Método: revisão bibliográfica, constituindo-se em um ensaio teórico.

Principais contribuições: a importância da mensuração e comunicação dos resultados dos investimentos em responsabilidade social.

Categorias identificadas: mensuração, comunicação e impacto das práticas sociais na cadeia de valor. 
Lacunas ou sugestões de estudos: falta a conexão entre as práticas sociais corporativas e os negócios da empresa.

16) PORTER, M.E; VANDER DER LINDE, C. Green and competitive: ending the stalemate. Harvard Business Review, v.73, n.5, pp. 120-133, 1995.

Objetivo: refletir sobre o trade-off entre ecologia versus economia.

Método: revisão bibliográfica, constituindo-se em um ensaio teórico.

Principais contribuições: apresenta impacto dos regulamentos ambientais na competitividade, demonstrando que as melhorias ambientais podem beneficiar os processos e a produtividade.

Categorias identificadas: produtividade, inovação, leis ambientais e competitividade.

Lacunas ou sugestões de estudos: desenvolver um framework mostrando os impactos positivos e negativos dos regulamentos ambientais.

17) YAACOB, Mohd R. A preliminary study of green micro-entrepreneurs in Kelatan, Malaysia. International Journal of Business and Management, v.5, n.3, pp. 81-88, 2010.

Objetivo: verificar quais são os fatores que puxam e/ou empurram os empreendedores verdes, que estratégias são adotadas, quais são as rotinas de empresários verdes, quais os desafios enfrentados pelos empresários e quais as perspectivas para os negócios verdes.

Método: revisão bibliográfica, pesquisa qualitativa e entrevistas com duas micro-empresas verdes.

Principais contribuiç̃ões: expansão de empreendedores verdes no local estudado.

Categorias identificadas: empreendedor verde, itens recicláveis e negócio verde.

Lacunas ou sugestões de estudos: realizar mais entrevistas para o aprofundamento do estudo.

18) YILMAZ, Ayse K. The corporate social responsibility practice in the Turkish Automotive Distribution Companies. International Journal of Business and Management, v.3, n.6, pp. 139-147, 2008.

Objetivo: investigar os esforços que estão sendo realizados pelas empresas de distribuição automotiva da Turquia.

Método: revisão bibliográfica, pesquisa qualitativa e estudo de caso em três empresas.

Principais contribuições: despertar maior sensibilização quanto à aplicação das práticas e princípios de responsabilidade social entre as empresas de distribuição automotiva na Turquia, investidores e reguladores.

Categorias identificadas: sustentabilidade corporativa e responsabilidade social corporativa.

Lacunas ou sugestões de estudos: construção de um framework com a integração das duas categorias.

19) ZILAY, Gyula. Toward sustainability: the role of higher education. Clean Technologies and Environmental Policiy Journal, $8: 1-2,2006$.

Objetivo: refletir sobre o tema educação para sustentabilidade no nível superior de ensino.

Método: revisão bibliográfica, constituindo-se em um ensaio teórico.

Principais contribuições: importância da integração do desenvolvimento sustentável com o currículo no ensino superior.

Categorias identificadas: educação no nível superior, currículo e desenvolvimento sustentável.

Lacunas ou sugestões de estudos: estudar a falta de integração entre o currículo no nível de educação no ensino superior com o desenvolvimento sustentável.

20) ZHANG, Z.; TIAN, X. Necessarity of practicing green manufacturing in iron industry from the point of social responsibility. International Journal of Business and Management, v.3, n.12, pp. 142-145, 2008.

Objetivo: analisa a relação entre a manufatura verde e a responsabilidade social corporativa, verificando os efeitos da manufatura verde em um grupo do segmento de ferro.

Método: revisão bibliográfica e pesquisa quantitativa.

Principais contribuições: mudar a percepção de que a indústria de ferro consume alta energia e polui o meio ambiente.

Categorias identificadas: manufatura verde e responsabilidade social corporativa.

Lacunas ou sugestões de estudos: construção de um framework com a integração das duas categorias.

Fonte: elaborado pela autora (2012) 